\title{
A KINETIC MODEL OF INTERVERTEBRAL STRESS DURING LIFTING*
}

\author{
G. A. WOOD \\ Department of Exercise Science, University of Massachusetts, U.S.A. \\ and \\ K. C. HAYES \\ Department of Kinesiology, University of Waterloo, Canada
}

\begin{abstract}
A biomechanical model of a simple lifting motion is presented in which the forces and moments of force acting about $\oint^{\infty}$ the L4-L5 vertebral articulation were determined from kinetic and kinematic data. Derivation of the forces due to motion permitted a unique method for estimating intervertebral stress during each phase of the lift and provided a logical extension to an earlier static model of intervertebral stress presented by Troup (13). The intervertebral force was + found to have a maximum value of over $400 \mathrm{~kg}$ during the initial phase of the lift. By partitioning this force into its $\supset$ shearing and compressional components, it was possible to determine quantitatively the lumbar stress involved in lifting. The values are discussed briefly in relation to the aetiology of back injuries and some of the predictions and applications of the dynamic model are also considered.
\end{abstract}

\section{Introduction}

Within the past decade there has been renewed interest in the prevalence and aetiology of lower back pain associated with the lifting of weights ${ }^{1}$. Extensive studies by Kotani et al (5) attest to the high incidence of spondylolysis, prolapsed disc, and other injuries to the vertebral column and its associated structures in competitive weight lifters. The risk of degenerative and traumatic lesions of the spine is, however, not confined to those engaged in competitive lifting as athletes in many different sports routinely incorporate weight training as part of their preparation. Furthermore, as Troup (14) has pointed out, young and inexperienced lifters represent another high risk population. The dangers associated with lifting in industrial and home settings are also well recognized.

Investigations of the predisposing factors have customarily employed a variety of experimental approaches including numerous types of biomechanical analysis $(2,11,12,13,15)$. Identification of the magnitude and direction of forces, and moments of force, about certain joints is important for understanding the aetiology of lesions and finds immediate application in the prevention and treatment of injuries and in the design of training and rehabilitation programmes.

In 1965 Troup (13) presented a model for calculating

\footnotetext{
${ }^{1}$ This view is supported by the fact that only a few years ago a whole symposium was devoted to "Risks of Weight Lifting and Training in Young People", the proceedings of which appeared in Brit.J.Sports Med. 5 (1) 1970.
}

the compressional forces on the intervertebral disc $\overrightarrow{0}$ between the second and third Lumbar vertebrae (L2-L3). This model gave consideration to all the static forces acting on the system; an approach which may be justified under certain circumstances (see for example reference (14), p. 30). However, in the majority of instances, complete analysis of the stress imposed upon $\mathbb{Q}$ the vertebral structures is dependent upon consideration $\vec{\overrightarrow{ }}$ of the forces due to motion, the so called inertial forces. Recently, techniques have been made available which permit complete and thorough analysis of all gravitational and inertial forces acting upon selected anatomical landmarks. The use of the computer naturally expedites the lengthy computation involved (9).

We have employed the dynamic model approach, which originates from the works of Dempster (3) and Plagenhoef (9), to determine the intra-articular forces acting upon the lumbar intervertebral discs (L4-L5). By $\frac{7}{0}$ utilizing the value of the resultant inertial (and gravitational) force in estimating intervertebral stress, N the logical extension of Troup's static model is accomplished. In addition, we have apportioned the intervertebral stress into compression and shearing $\omega$ components since recent work implicates the latter 0 component in the aetiology of certain traumatic and $\theta$ degenerative lesions of the spine, noteably spondylolisthesis (14).

\section{Method}

Data were obtained through cinematographical motion $\stackrel{\overparen{D}}{\mathbb{D}}$ analysis techniques (10), enabling computation of the forces and joint moments of force operating during the 


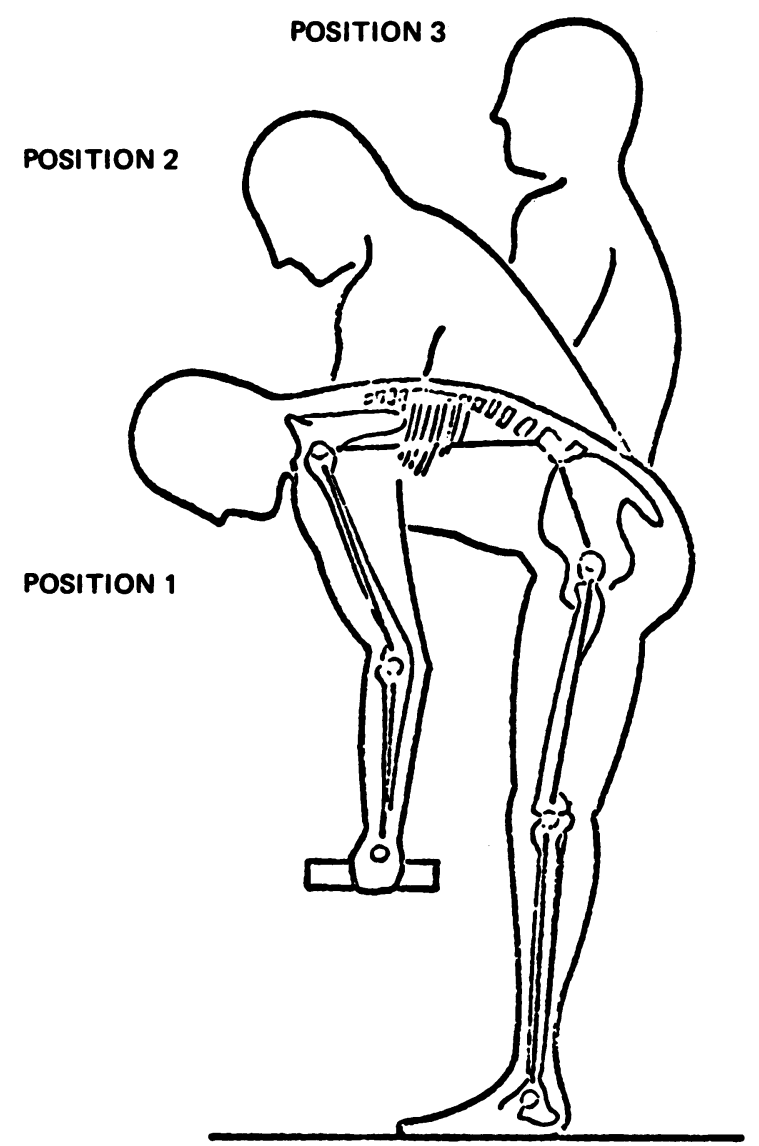

Figure 1: Anatomical Link System

motion. Body segments, as viewed in the sagittal plane, were treated as a mechanical link system (Figure 1), having the biomechanical properties presented in Table I.

Table 1

\section{Biomechanical Properties of Anatomical Link System}

\begin{tabular}{|c|c|c|c|c|}
\hline SEGMENT & $\begin{array}{l}\text { Weight* } \\
\text { (W) (kg) }\end{array}$ & $\begin{array}{l}\text { Length } \\
\text { (L) }(\mathrm{cm})\end{array}$ & $\begin{array}{l}\text { Centre of } \\
\text { Gravity }{ }^{+}(r) \\
(\% \text { of } L)\end{array}$ & $\begin{array}{l}\text { Radius of } \\
\text { Gyration }+(k) \\
\text { (\% of } L)\end{array}$ \\
\hline $\begin{array}{l}\text { Forearms } \\
+ \text { Load }\end{array}$ & 8.47 & 29.0 & 90.0 & 95.0 \\
\hline Upper Arms & 5.00 & 28.0 & 43.6 & 54.2 \\
\hline $\begin{array}{l}\text { Thorax + } \\
\text { Abdomen }\end{array}$ & 30.90 & 41.3 & 77.4 & 93.9 \\
\hline Pelvis & 10.10 & 18.0 & 36.0 & 41.0 \\
\hline Thighs & 15.52 & 42.8 & 56.7 & 65.3 \\
\hline Shanks & 6.58 & 44.6 & 56.7 & 64.3 \\
\hline
\end{tabular}

*Obtained through the application of segment densities (3) to volumetric data derived from water displacement (plethysmography).

+From Dempster (3).

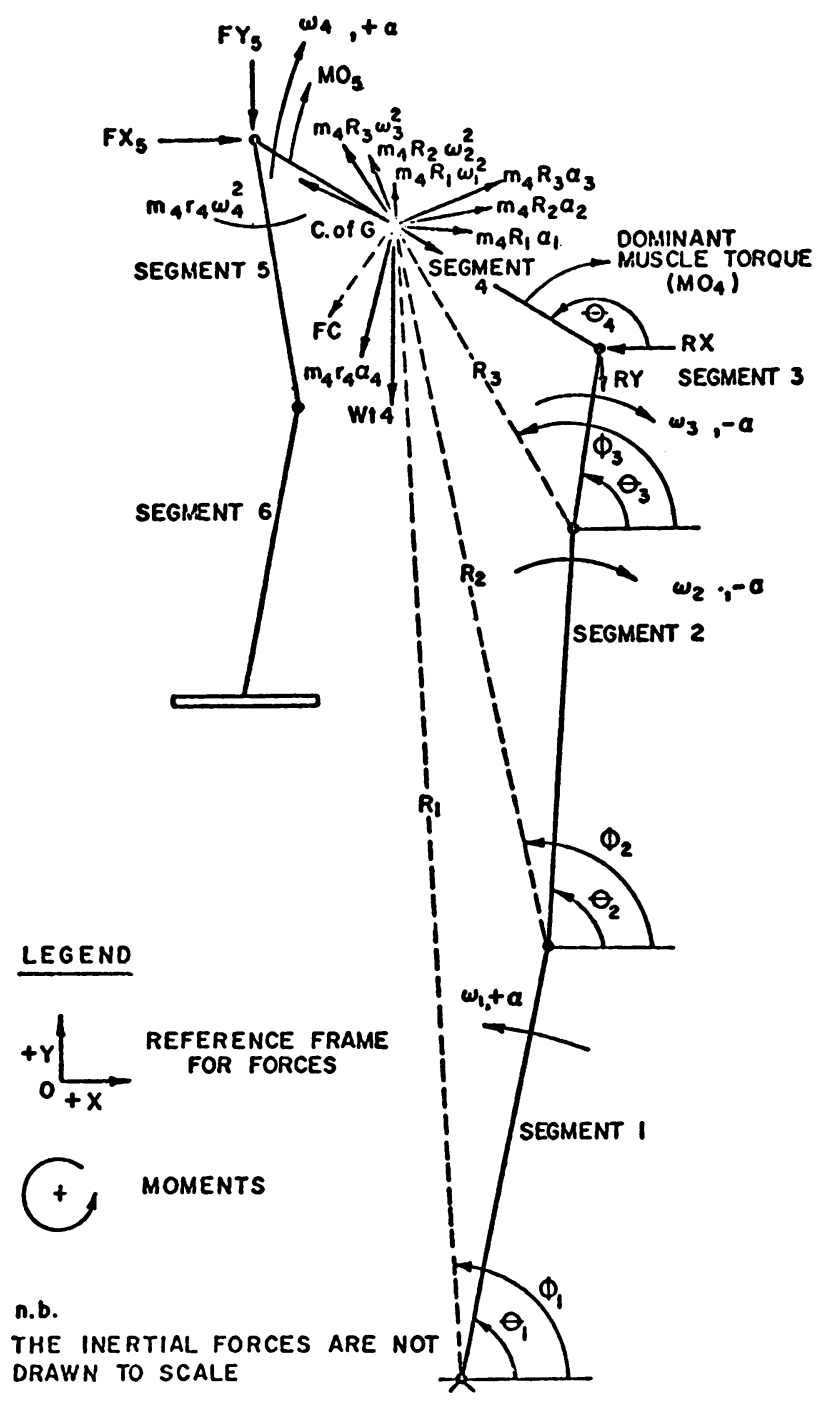

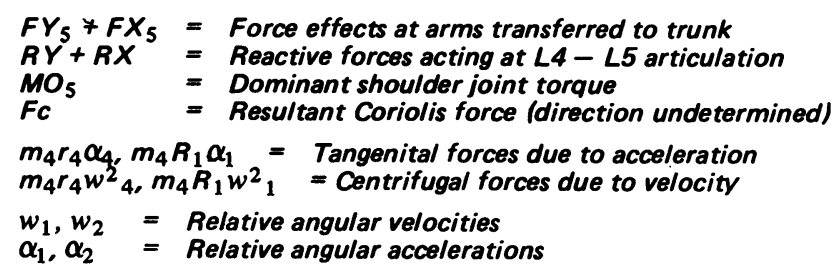

Fig. 2: Diagram of forces and moments of force acting upon the trunk during lift

Analysis of motion film (taken at 64 frames per second with a Pathé Professional Reflex $16 \mathrm{~mm}$ camera) permitted the measurement, in small time increments, of the angular displacement of each body segment during lifting. Appropriate smoothing of displacement data, 
within an error tolerance of $5 \%$, was achieved through the application of the curve fitting procedures taken from Kuo (6) and using an algebraic polynomial of five. Absolute and relative angular velocities and accelerations were then mathematically determined through differentiation of the smoothed displacement curve (1st and 2 nd derivative respectively).

Segment forces and joint movement of force were calculated taking into consideration all inertial as well as gravitational effects. These forces in a six segment motion are quite numerous, and data reduction in this study was greatly facilitated through the use of a computer programme for biomechanical motion analysis which performs all the above operations from raw displacement data. Figure 2 shows all the forces acting upon the trunk segment which were included in trunk force and torque computations, the equations for which are presented below.

Conventional $\mathrm{X}, \mathrm{Y}$ co-ordinate nomenclature was used in defining the orthogonal force components and a counterclockwise moment of force was defined as a positive effect.

The lift studied in the development of the model involved the subject (male, $69 \mathrm{~kg}, 1.77 \mathrm{M}$ ) picking up a $5.67 \mathrm{~kg}$ load from a $45 \mathrm{~cm}$ bench. At the position of greatest forward lean the trunk was at an angle of $161^{\circ}$ from the right horizontal. From here the subject lifted the weight keeping both his legs and back extended until he was in an erect standing position. This movement was performed at a moderately slow speed with an average angular velocity (absolute) of the trunk of $60^{\circ}$ per sec. and reached a maximum instantaneous velocity of $74^{\circ}$ per sec. (absolute).

\section{Results}

\section{Calculation of L4-L5 Intervertebral Force}

The moments of force acting about the L4-L5 vertebral joint at successive stages in the lift are depicted in Figure 3. If it is assumed that the lever arm of the erectores spinae group is approximately $6 \mathrm{~cm}$ (13) (the nucleus pulposus of the fifth lumbar disc being the fulcrum), and that the predominant angle of pull is parallel to the vertebral column, then the contractile force of the back extensors may be calculated for any lifting position. The moments of force at the L4-L5 articulation are divided by the effective lever arm of the erectores spinae 16.0 $\mathrm{cm})$; thus, at the point in the lift where L4-L5 torque was greatest (position 4), the contractile force of the back extensors was found to be: $(23.3 \mathrm{kgM} / .06 \mathrm{M})=$ $388.3 \mathrm{~kg}$. The intervertebral stress can then be derived from the algebraic summation of the vertical and horizontal components of the forces acting upon the trunk, viz. the contractile force of the back extensors, the forces due to gravity, and the forces due to the motion. This method is illustrated in Figure 4 for the

$$
\begin{aligned}
& F x_{4}=F x_{5}-m_{4} r_{4} \alpha_{4} \operatorname{Sin}\left(180-\theta_{4}\right)-m_{4} r_{4} \omega_{4}^{2} \operatorname{Cos}\left(180-\theta_{4}\right)-m_{4} R_{3} \omega_{3}^{2} \operatorname{Sin}\left(180-\phi_{3}\right) \\
& -m_{4} R_{2} \omega_{2}^{2} \operatorname{Sin}\left(180-\phi_{2}\right)-m_{4} R_{1} \omega_{1}^{2} \operatorname{Sin}\left(180-\phi_{1}\right)+m_{4} R_{3} \alpha_{3} \operatorname{Cos}\left(180-\phi_{3}\right) \\
& +m_{4} R_{2} \alpha_{2} \operatorname{Cos}\left(180-\phi_{2}\right)+m_{4} R_{1} \alpha_{1} \operatorname{Cos}\left(180-\phi_{1}\right) \pm \text { Coriolis Forces } \\
& F y_{4}=-W t_{4}-F_{5}-m_{4} r_{4} \alpha_{4} \operatorname{Cos}\left(180-\theta_{4}\right)+m_{4} r_{4} \omega_{4}^{2} \operatorname{Sin}\left(180-\theta_{4}\right)+m_{4} R_{3} \omega_{3}^{2} \operatorname{Cos}\left(180-\phi_{3}\right) \\
& +m_{4} R_{2} \omega_{2}^{2} \operatorname{Cos}\left(180-\phi_{2}\right)+m_{4} R_{1} \omega_{1}^{2} \operatorname{Cos}\left(180-\phi_{1}\right)+m_{4} R_{3} \alpha_{3} \sin \left(180-\phi_{3}\right) \\
& +m_{4} R_{2} \alpha_{2} \operatorname{Sin}\left(180-\phi_{2}\right)+m_{4} R_{1} \alpha_{1} \operatorname{Cos}\left(180-\phi_{1}\right) \pm \text { Coriolis Forces } \\
& \mathrm{MO}_{4}+\mathrm{m}_{4} \mathrm{k}_{4}^{2} \alpha_{4}+\mathrm{wt}_{4} \times \mathrm{r}_{4} \operatorname{Sin}\left(\theta_{4}-90\right)+\mathrm{F}_{\mathrm{y}_{5}} \times \ell_{4} \operatorname{Sin}\left(180-\theta_{4}\right)-\mathrm{m}_{4} \mathrm{R}_{3} \omega_{3}^{2} \operatorname{Sin}\left(\theta_{4}-\phi_{3}\right)_{r_{4}} \\
& -m_{4} R_{2} \omega_{2}^{2} \sin \left(\theta_{4}-\phi_{2}\right) r_{4}-m_{4} R_{1} \omega_{1}^{2} \sin \left(\theta_{4}-\phi_{1}\right) r_{4}-m_{4} R_{3} \alpha_{3} \cos \left(\theta_{4}-\phi_{3}\right) r_{4} \\
& -m_{4} R_{2} \alpha_{2} \operatorname{Cos}\left(\theta_{4}-\phi_{2}\right) r_{4}-m_{4} R_{1} \alpha_{1} \operatorname{Cos}\left(\theta_{4}-\phi_{3}\right)-F_{x_{5}} x_{4} \operatorname{Cos}\left(180-\theta_{4}\right) \pm \text { Coriolis; Torque } \\
& +\mathrm{MO}_{5}=0
\end{aligned}
$$




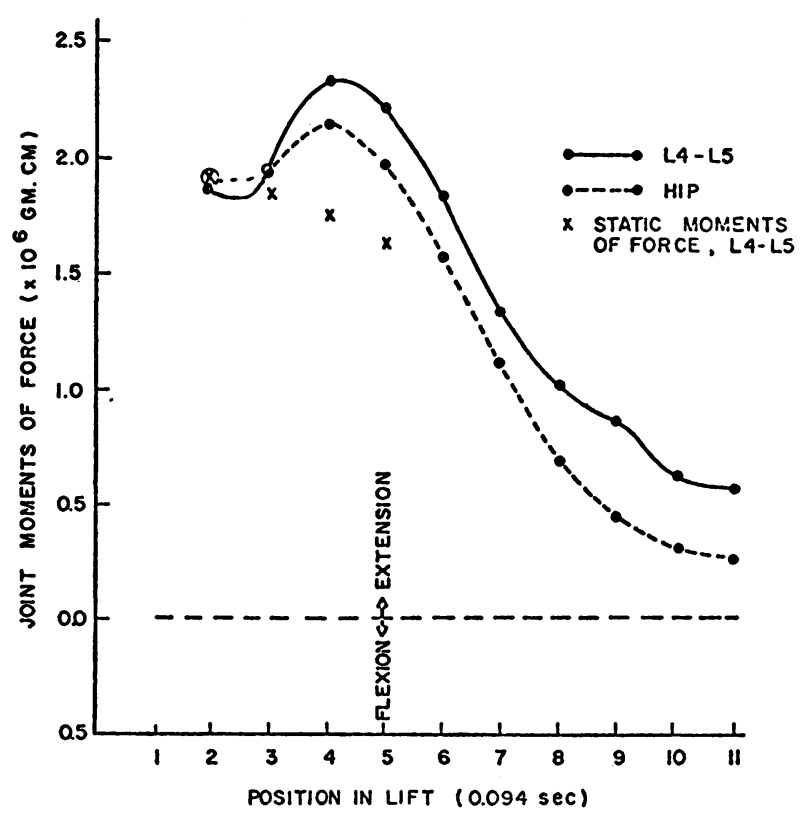

Figure 3: MOMENTS OF FORCE ABOUT L4-L5 AND HIP JOINTS DURING LIFT. Values obtained for Positions 1 and 12 have been omitted as they were artificially low; a function of the curve fit procedures.

position of greatest torque. The intervertebral force $\left(F_{\mathbf{u}}\right)$ was calculated to have a magnitude of $416.5 \mathrm{~kg}$ applied at a 7 degree angle to the trunk during this phase of the lift (see Figure 4).

\section{Discussion}

The importance of hip extension in the initial stages of the lift is evident from the comparison of moments of force acting about the lumbar spine and hip joint, presented in Figure 3. It has been reported elsewhere (4, 8) that during this period of full flexion of the spine, electromyographic activity in the erectores spinae group is minimal or non-existent. It would appear that a large part of the rotational stress of approximately $18 \mathrm{kgM}$ found to be acting about the L4-L5 joint at this time is accommodated by ligamentous structures.

After the lift had been initiated by the muscles producing hip extension and backward tilting of the pelvis there appeared to be a shift of maximum stress away from the hips and toward the lumbar vertebrae. The maximum moments of force acting about the L4-L5 vertebral articulation occurred during this early acceleratory phase of trunk extension (position 3-5) and at a point which coincides with Floyd's and Silver's (4) observation of maximal electromyographic activity in the erectores spinae.

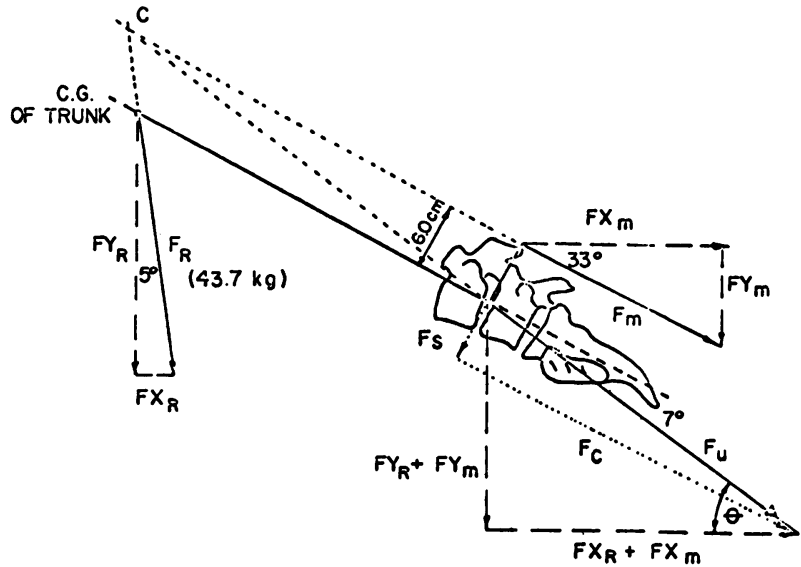

$$
\begin{aligned}
& \text { FY - VERTICAL COMPONENT OF FORCE } \\
& \text { FX - hOAIZONTAL CONPONENT OF FORCE } \\
& F_{R} \text { - RESULTANT OF ALL gRAVITATION AND } \\
& \text { INERTIAL FORCES ACTING UPON } \\
& \text { TRUNiS } \\
& F_{m} \text { - CONTAACTiLE FORCE OF EACK } \\
& \text { EXTEi:SONS } \\
& F_{U} \text { - MNTERVERTEESAL (bonc on bonC) } \\
& \text { FONC: } \\
& F_{S} \text { - SHefniNe conpoNent of } F_{L} \\
& F_{C} \text { - CONPAESSIONAL CON:PONENT } \\
& \text { of } F_{L}
\end{aligned}
$$

Figure 4: Derivation of L4-L5 Intervertebral Forces for Position of Greatest Torque

Calculation of the magnitude of the contractile force of the erectores spinae at the phase of the lift where maximum torque was generated (Figure 4) was dependent upon the assumption that the pull of the back extensors was parallel to the vertebral column. The appropriateness of this assumption was verified by the finding that the lines of action of the three non-parallel trunk forces were virtually concentric (point $C$, Figure 4); a condition which must necessarily be fulfilled in a free body diagram, being a static representation of a dynamic system (see figures 1 and 4 ).

It should also be noted that the value obtained for the force of the erectores spinae group only approximates the absolute muscular force under conditions where the segment motion is relatively slow, as in the present case. As the moments of force computed represent a differential of agonistic and antagonistic forces, then a more rapid motion would necessitate a consideration of forces contributing to joint stabilization in order to obtain the absolute contractile force.

The intervertebral stress has been further apportioned into shearing $\left(F_{s}\right)$ and compressional force $\left(F_{c}\right)$ components. The shearing force, whose value has been 
calculated as $36.5 \mathrm{~kg}$ for position 4 is of special significance as it is this component which has been considered responsible for the degenerative and traumatic lesions of the pars interarticularis (14).

Integrity of the L4-L5 articulation is dependent upon the ratio of shearing to compression forces; the smaller this ratio the less traumatic the load. This ratio is directly proportional to the size of the angle $\theta$ in Figure 4 , which, for a given torque value, can be seen to be a function of total FX and FY components of force. It therefore follows that any factor operating to a) increase the total FY force, for example, a heavier load or more rapid trunk acceleration; or b) decrease the total FX force, will increase the traumatic stress upon the L4-L5 articulation while the trunk is in a semi-horizontal position. It was interesting to note that subject in the present study effectively increased the total FX force component during the lifting phase of the maximum L4-L5 torque by briefly decelerating the arm motion. The resulting positive $F X$ force was transmitted to the trunk and served to reduce L4-L5 stress during this vulnerable phase of lifting (see $F X_{R}$, Figure 4).

To illustrate further the importance of including dynamic aspects in a biomechanical analysis, static torque values about the L4-L5 vertebral joint were calculated for positions of maximum dynamic torque. These values, superimposed on Figure 3, can be seen to be somewhat less than corresponding dynamic values.

Inspection of Figure 2 shows that the majority of inertial vectors acting upon the trunk during the critical phase of the motion (position 4) were assisting the action of the back extensors. However, most of these forces were of low magnitude; originating from the slow relative angular motions of the shank, thigh and pelvis. The largest and consequently most significant vector was that caused by the motion of the trunk $\left(m_{4} r_{4} \alpha_{4}\right)$. This tangential force, which is dependent upon the acceleration rather than the velocity of motion, provided the principal opposing force to the back extensors; in conjunction with the weight vector of the trunk. The action of the back extensors was in essence to overcome these inertial $\left(m_{4} r_{4} \alpha_{4}\right)$ and gravitational forces $\left(w t_{4}\right)$ and was slightly assisted in this by the forces $\left(m_{4} R_{3} \alpha_{3}\right.$, $m_{4} R_{1} \alpha_{1}$, etc) of the lower limbs.

It can be seen from the analysis so far presented that the contributions of the arms and the legs both appeared beneficial to the muscle action of the back extensors. It also becomes apparent exactly how the motion of the limbs contribute to the efficiency of lifting. This contribution has long been known empirically but the present model aids in the quantification of these effects. Furthermore, the model that has been presented enables further simulation of the lifting motion on the computer, and permits varying the accelerations and velocities of various body segments to provide prediction of subsequent effects on the intervertebral discs. This process is being carried out ${ }^{1}$ currently with a view to optimizing the lifting motion with respect to some predetermined criteria viz shearing force and/or compression force. Further work, with a larger number of subjects, is also under way to test the predictions of this model and to outline normative data on the various force components under a variety of lifting conditions.

The surprisingly large value of the L4-L5 intervertebral force found in the present study may be reduced partially by intra-truncal pressure. The work of Davis et al. (1) suggests that with increased stress, intra-truncal pressures also increase and may play an important role in relieving the load on the lumbar spine. In fact, these pressures have been claimed to reduce the force on the lumbosacral disc during the lifting of a 200 Ib load by as much as 30 per cent (8). If this is the case, the important role of well developed abdominal musculature, in addition to the obviously needed back extensor strength becomes evident.

${ }^{1}$ Depertment of Kinesiology, University of Waterloo.

\section{REFERENCES}

1. DAVIS, P. R. and J. D. G. TROUP, (1964) Pressures in the Trunk Cavities When Pulling, Pushing and Lifting. Ergonomics 7: 465-474.

2. DAVIS, P. R., J. D. G. TROUP and J. H. BURNARD, (1965) Movements of the Thoracic and Lumbar Spine When Lifting: A Chrono-cyclophotographic Study. Journal of Anatomy 99: 13-26.

3. DEMPSTER, W. T., (1955) Space Requirements of the Seated Operator. WADC Technical Report, pp. 55-159.

4. FLOYD, W. F. and P. H. S. SILVER, (1955) The Function of the Erectores Spinae Muscles in Certain Movements and Postures in Man. Journal of Physiology 129: 184-203.

5. KOTANI, P. T., N. ICHIKAWA, W. WAKABAYASHI, T. YOSHII and M. KOSHIMUNE, (1971) Studies of Spondylolysis Found among Weightlifters. British Journal of Sports Medicine 6: 4-8. 
6. KUO, S. (1965) Numerical Methods and Computers, Addison Wesley, Reading, Massachusetts, pp. 234-235.

7. MORRIS, J. M., D. B. LUCAS, and B. BRESLER, (1961) Role of the Trunk in Stability of the Spine. Journal of Bone and Joint Surgery 43A: 327-351.

8. MORRIS, J. M., G. BENNER and D. B. LUCAS, (1962) An Electromyographic Study of the Intrinsic Muscles of the Back in Man. Journal of Anatomy 96: 509-520.

9. PLAGENHOEF, S. C., (1968) Computer Programs for Obtaining Kinetic Data on Human Movement. Journal of Biomechanics 1: 221-234.

10. PLAGENHOEF, S. C. (1971) Patterns of Human Motion: A Cinematographic Analysis. Prentice-Hall, Inc. New Jersey.

11. TICHAUER, E. R., (1968) The Efficiency of the Human Machine in Work Situations, in Research Conference on Applied Work Physiology, New York University Medical Centre, pp. 17-51.

12. TICHAUER, E. R. (1971) A Pilot Study of the Biomechanics of Lifting in Simulated Industrial Work Situations. Journal of Safety Research 3: 98-115.

13. TROUP, J. D. G. (1965) Relation of Lumbar Spine Disorders to Heavy Manual Work and Lifting. The Lancet 1: 857-861.

14. TROUP, J. D. G. (1970) Functional Anatomy of the Spine. British Journal of Sports Medicine 5: 27-33.

15. World Health Organization, (1969) Optimal Physical Performance Capacity in Adults. WHO Technical Report Series; Report No. 436: 18-19. 